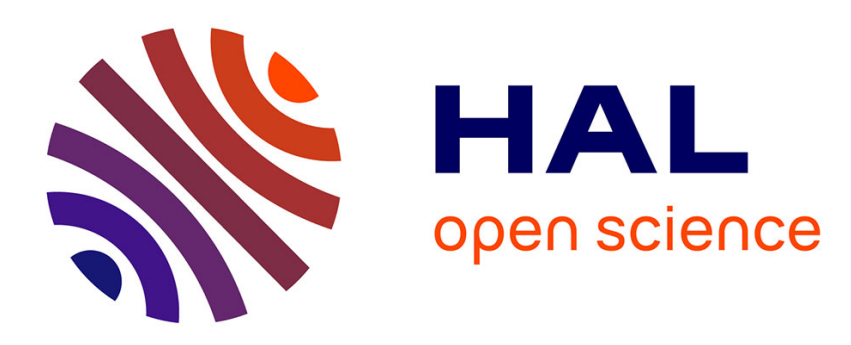

\title{
Local behavior of an AISI 304 stainless steel submitted to in situ biaxial loading in SEM
}

Célia Caer, Raphaël Pesci

\section{To cite this version:}

Célia Caer, Raphaël Pesci. Local behavior of an AISI 304 stainless steel submitted to in situ biaxial loading in SEM. Materials Science and Engineering: A, 2017, 690, pp.44-51. 10.1016/j.msea.2017.02.087 . hal-01485067

\section{HAL Id: hal-01485067 \\ https://hal.science/hal-01485067}

Submitted on 8 Mar 2017

HAL is a multi-disciplinary open access archive for the deposit and dissemination of scientific research documents, whether they are published or not. The documents may come from teaching and research institutions in France or abroad, or from public or private research centers.
L'archive ouverte pluridisciplinaire HAL, est destinée au dépôt et à la diffusion de documents scientifiques de niveau recherche, publiés ou non, émanant des établissements d'enseignement et de recherche français ou étrangers, des laboratoires publics ou privés. 


\title{
Local behavior of an AISI 304 stainless steel submitted to in situ biaxial loading in SEM
}

\author{
C. Caër*, R. Pesci \\ Arts et Métiers ParisTech, Laboratoire d'Étude des Microstructures et de Mécanique des Matériaux (LEM3), UMR CNRS 7239, 57070 Metz, France
}

\begin{abstract}
A B S T R A C T
The microstructural response of a coarse grained AISI 304 stainless steel submitted to biaxial tensile loading was investigated using SEM and X-ray diffraction. The specimen geometry was designed to allow for biaxial stress state and incipient crack in the center of the active part under biaxial tensile loading. This complex loading was performed step by step by a micromachine fitting into a SEM chamber. At each loading step FSD pictures and EBSD measurements were carried out to study the microstructural evolution of the alloy, namely grain rotations and misorientations, stress-induced martensite formation and crack propagation. According to their initial orientation, grains are found to behave differently under loading. Approximately $60 \%$ of grains are shown to reorient to the [110] $\mathrm{Z}$ orientation under biaxial tensile loading, whereas the $40 \%$ left undergo high plastic deformation. EBSD and XRD measurements respectively performed under loading and on the post mortem specimen highlighted the formation of about $4 \%$ of martensite.
\end{abstract}

\section{Introduction}

The drive toward miniaturized systems in various engineering fields motivates the study of materials behavior close to their industrial scales. Moreover most of the phenomena occurring at the macroscopic scale result from mechanisms (phase transformation, cracking,..) happening at the microscopic scale.

Numerous experimental means and techniques have therefore been adapted from macroscopic to nanometric scale. This allows to study the influence of environmental constraints such as mechanical loading $[1,2]$, temperature $[3,4]$, speed $[5,6]$ or even irradiation $[7,8]$ on the material behavior at a small scale [9]. Numerous studies can be found in the literature regarding the microstructural evolution of materials under in situ uniaxial tensile tests $[10,11]$. However, during their real service life, materials are usually loaded according to far more complex loading paths than uniaxial tension. Different mechanical loading paths available on macroscopic tests benches (bulge test [12], bending [13], ...) were therefore adapted to smaller scales.

The present work aims at studying microstructural features evolution under a specific complex mechanical loading, namely equi-biaxial tensile loading, using laboratory facilities. This kind of study has already been developed for Synchrotron $[14,15]$ or neutron diffraction $[16,17]$; however it is important to set up such a loading path in more ordinary equipment such as Scanning Electron Microscopes (SEM). This work involves an approach that combines Electron Backscattered
Diffraction (EBSD) and X-ray diffraction (XRD).

The second section of this paper focuses on the presentation of experimental details, advanced techniques and materials used in this work. AISI 304 steel was used in this study as it is the most extensively used steel finding applications in the automotive and nuclear industries in particular. In situ experiments were performed using a miniature biaxial tensile test bench fitted in the SEM and under X-ray diffraction.

Although reference standards for uniaxial tension [18] or bending [19] impose to use specific specimen geometries, the current standard for biaxial tensile tests [20] is less constraining by allowing the use of alternative specimen geometries [21,22]. The third part of this paper therefore presents a convenient specimen geometry determined from Finite Element Method (FEM) simulations to in situ validation in SEM. The newly designed sample geometry should allow for a biaxial stress state in the active part of the specimen and crack initiation in the center of said active part.

From these in situ biaxial tensile tests performed in SEM, the study of mechanical and microstructural features evolution under a complex loading path was performed. Microstructural evolution was first observed according to features such as grain reorientations and misorientations under loading. A particular focus was also made on the stress-induced martensitic transformation. Finally this study focuses on crack initiation and propagation.

\footnotetext{
* Correspondence to: Arts et Métiers ParisTech, 4 rue Augustin Fresnel, 57070 Metz, France. E-mail address: celia.caer@gmail.com (C. Caër).
} 
Table 1

Chemical composition of the AISI 304 stainless steel (\% weight).

\begin{tabular}{llllllll}
\hline $\mathrm{C}$ & $\mathrm{Mn}$ & $\mathrm{Cr}$ & $\mathrm{Ni}$ & $\mathrm{Mo}$ & $\mathrm{Cu}$ & $\mathrm{Si}$ & $\mathrm{Nb}$ \\
\hline 0.006 & 1.54 & 18.47 & 8.3 & 0.3 & 0.37 & 0.48 & 0.027 \\
\hline
\end{tabular}

\section{Materials and methods}

\subsection{Material processing and preparation}

The investigated alloy is an austenitic AISI 304 stainless steel rolled in cylinders of $100 \mathrm{~mm}$ diameter; the chemical composition is given in Table 1. This material showed in the as-received state a yield strength $\sigma_{\mathrm{y}}=325 \mathrm{MPa}$, a maximum strength $\sigma_{\mathrm{m}}=1000 \mathrm{MPa}$ and a Young modulus $\mathrm{E}=200 \mathrm{GPa}$ [23]. The as-received material was examined using EBSD which showed a too fine-grained microstructure for the study to be carried out. The steel cylinder was therefore annealed in vacuum at $1200{ }^{\circ} \mathrm{C}$ for $1 \mathrm{~h}$ to increase the grain size up to an average of $300 \mu \mathrm{m}$.

Thanks to electro-discharge machining, slices were cut out of the steel cylinders and samples were machined from the slices.

Prior to any EBSD analysis, sample surfaces were carefully prepared. Specimens were first mechanically polished with decreasing SiC papers and diamond particle pastes. The final mechanical polishing was performed with a $1 \mu \mathrm{m}$ diamond paste. The samples were finally electropolished in a solution of $\left(\mathrm{C}_{2} \mathrm{H}_{4} \mathrm{O}_{4}+\mathrm{H}_{2} \mathrm{O}\right)$ at $16 \mathrm{~V}$ for $1 \mathrm{~min}$.

\subsection{Biaxial tensile testing}

Samples for macroscopic biaxial tensile tests were mounted on a servo-hydraulic multiaxial testing machine developed by INSTRON. The loading was chosen to follow a balanced biaxial tensile loading path $\left(\varepsilon_{\mathrm{TD}} / \varepsilon_{\mathrm{RD}}=1\right)$ path up to failure. The experiments were conducted using a constant strain rate of $1.5^{*} 10^{-2} \mathrm{~s}^{-1}$. An infrared camera was placed in front of the specimen in the biaxial tensile bench in order to follow the temperature evolution and the associated stress concentrations during the whole loading.

In situ mechanical tests were performed thanks to a micromachine (model called "Proxima") developed by the company MICROMECHA. This machine, dedicated to mechanical testing in SEM and with XRD (Fig. 1), was fitted with a tensile biaxial set up for this study. In situ equi-biaxial tensile tests have been performed at low strain rates around $1.5^{*} 10^{-3} \mathrm{~s}^{-1}$. This experimental setup allows for:

- The quantification of the amount of martensite formed during loading when placing the post-mortem specimen on a XRD goniometer.

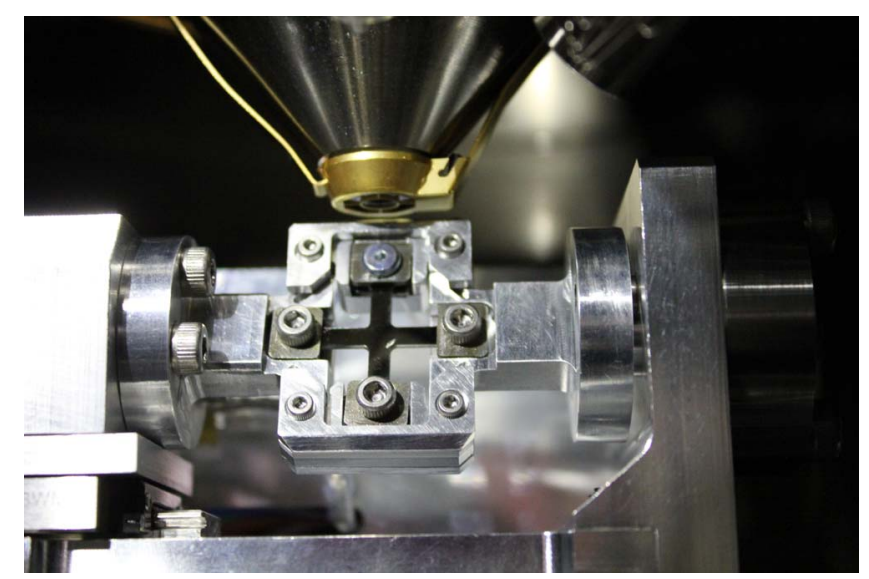

Fig. 1. Micromachine from MICROMECHA company (Proxima model) mounted in a SEM and fitted with the tensile biaxial setting.
Table 2

Planes analyzed and corresponding $2 \theta$ angles for both austenite and martensite.

\begin{tabular}{lllll}
\hline Phase & Austenite & \multicolumn{3}{c}{ Martensite } \\
\hline Plane analyzed & $\{200]$ & $\{220\}$ & $\{200\}$ & $\{211\}$ \\
$2 \theta$ angle (deg) & 79 & 128.7 & 107.1 & 154.1 \\
\hline
\end{tabular}

- The study of the microstructure evolution (texture, intragranular misorientations, plasticity, phase transformation...) during loading when mounting the micromachine into a SEM.

\subsection{X-rays diffraction technique}

XRD is a very efficient non-destructive technique which offers the opportunity to not only study crystallographic texture but also accurately quantify the volume fraction of phases and evaluate the level of residual stresses. XRD has been used in this study to measure the volume fraction of both austenite and martensite phases in the postmortem specimens following the ASTM E975-13 standard.

The volume fraction quantification of the two phases contained in AISI 304 steel has been performed with a PROTO iXRD goniometer fitted with a 1D detector by taking into account the intensity of the diffraction peaks of both austenite (A) and martensite (M); two peaks of each phase were retained as summed up in Table 2. Because of the two-phase microstructure of the steel, the sum of the volume fractions of austenite $\mathrm{V}_{\mathrm{A}}$ and martensite $\mathrm{V}_{\mathrm{M}}$ should be equal to 1 .

The volume fraction of austenite is obtained according to (Eq. (1)):

$\mathrm{V}_{\mathrm{A}}=\left(\frac{1}{q} \sum_{j=1}^{q} I^{A j} / R^{A j}\right) /\left(\frac{1}{p} \sum_{i=1}^{q p} I^{M i} / R^{M i}\right)+\left(\frac{1}{q} \sum_{j=1}^{q} I^{A j} / R^{A j}\right)$

where $\mathrm{I}^{\mathrm{Mi}}$ and $\mathrm{I}^{\mathrm{Ai}}$ are respectively the diffraction peak intensities of martensite and austenite. $\mathrm{R}^{\mathrm{Mi}}$ and $\mathrm{R}^{\mathrm{Ai}}$ are coefficients depending on the Lorentz Polarization and the Debye-Waller factors, multiplicity of the considered $\{h k l\}$ reflections and the crystal lattice of the phase [24].

The volume fraction of both austenite and martensite have been measured using a collimator $1 \mathrm{~mm}$ in diameter and a chromium tube $(\lambda=2.29 \AA)$ which allows a penetration depth of about $10 \mu \mathrm{m}$. The uncertainty in the phase fraction measurement is about $0.3 \%$.

\subsection{Scanning Electron Microscopy}

The device used in this study is a 7001 Field Electron Gun Scanning Electron Microscope from JEOL equipped with an Oxford EBSD CCD camera fitted with FSD detectors. EBSD data were post-treated with the software CHANNEL 5 from Oxford [25].

Given the coarse grain size, step size was set to $1 \mu \mathrm{m}$ and the voltage to $15 \mathrm{kV}$. The eventual field of view obtained was $1.2^{*} 1.2 \mathrm{~mm}$.

The biaxial tensile micromachine was set in the SEM and the loading was applied step by step until specimen failure. 15 steps were applied up to failure. SEM images, ESBD mappings and FSD images were performed at each loading step allowing for the microstructure characterization at each stop-off. An effort was made to keep the same area, namely the center of the specimen, under the field emission gun during the whole loading.

The EBSD technique was operated to study the evolution of [26]:

- grain reorientations and misorientations,

- phase transformation as the software was required to identify the crystal lattice of austenite (FCC) and martensite (BCC).

\section{Specimen geometry design for in situ loading in SEM}

This section details the process of specimen geometry design for biaxial tensile experiments. This specimen geometry should allow for: 
- biaxial stress state in the active part of the specimen

- maximum stress and therefore crack initiation in the center of the active part under equi-biaxial tensile loading.

Due to the cost of machining specimen at the microscopic scale, the geometry design of the specimen was first done at the macroscopic scale thanks to FEM simulations and experimental tests before being adapted to the SEM scale.

Numerous specimen geometries designed for biaxial tensile tests are found in the literature. Among those, some have been designed to obtain a homogeneous biaxial stress state in the gauge area either thanks to thickness reduction of the active part $[27,28]$ or slit cuts into the arms $[29,30]$. As the aim of the present study was to determine a macroscopic geometry that could also be adapted at the microscopic scale, the geometry with "slit cuts into the arms" geometry was considered as being too difficult to machine at the SEM scale. This study therefore focuses on reducing the volume of the gauge area to reach the aforementioned two conditions. Baptista et al. [31] used cruciform specimen showing round thickness reduction on both sides of the active part. They obtained a maximum stress leading to damage at the center of the gauge area. In the present study, one of the requirements was to keep one face perfectly flat for the specific EBSD surface preparation and observation. Then thickness reduction could not be operated on both sides of the specimen. As a consequence the specimen was re-designed with thickness reduction of only one side of the active part.

Several specimen geometries were designed and biaxially loaded thanks to FEM simulations. The complete model has been imported into the V6.13-2 Abaqus (Dassault Systèmes) finite element calculation software. An isotropic elastic constitutive law has been adopted to model the material. A general static step has been considered in order to load the specimen, in the same configuration that in experiments in terms of boundary conditions. The specimen has been meshed with C3D10 quadratic tetrahedron continuous and isoparametric finite elements with a minimum size of $0.1 \mathrm{~mm}$. This size allowed to have at least 3 elements in the thickness of the sample in order to well describe heterogeneous stress field. The geometry variations consisted in different shapes of the central thinned zone: round (cf. Fig. 2), square and clover were compared to specimens with no thickness reduction. Macroscopic specimens with these geometries were all tested; some of them showed some detrimental stress concentrations.

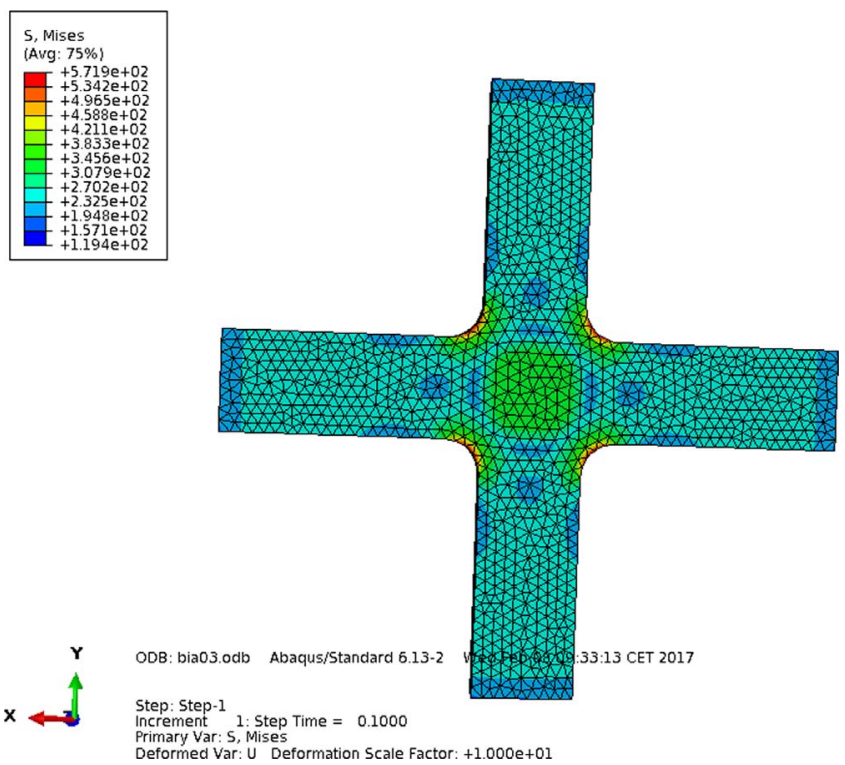

Fig. 2. FEM simulation of von Mises stress distribution on the rear side of a sample presenting a round thickness reduction and submitted to a proportional biaxial tensile loading. (a)
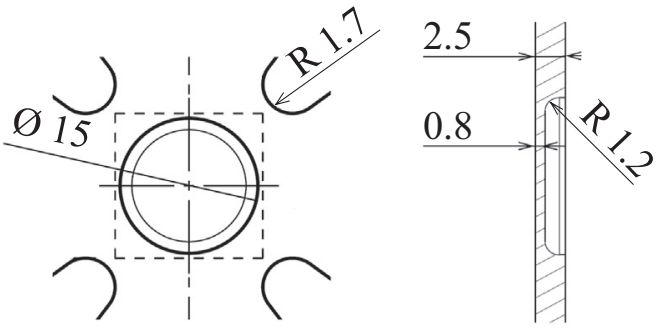

(b)

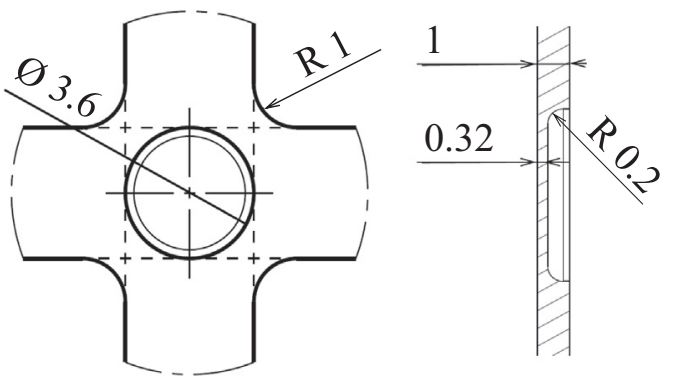

Fig. 3. (a) Geometry of the tensile biaxial specimen with circle thickness reduction (b) geometry of the SEM scaled specimen $(\mathrm{mm})$.

The most convenient geometry presented a round thickness reduction on one face of the specimen (32\% of the initial thickness remaining) as shown on Fig. 3a. This specimen geometry was then machined to be tested on a macroscopic biaxial tensile test bench following an equi-biaxial loading path. During loading, the infrared camera placed in front of the specimen showed an increase in temperature corresponding to stress concentration at the center of the gauge area. Just before fracture, the maximum stress was localized in the very center of the active part, leading to crack initiation at this point (cf. Fig. 4a). The specimen geometry presented in Fig. 3a suited design and testing requirements well, it was therefore adapted to the lower scale.

The final geometry of the in situ specimen was adapted from the macroscopic specimen geometry by a proportional reduction of the active part and a re-design of the arms in order to fit the micromachine clamping system (Fig. 3b). The active part is a $3.6 \mathrm{~mm}$ wide and $1 \mathrm{~mm}$ thick square showing a round thickness reduction in the center (a)

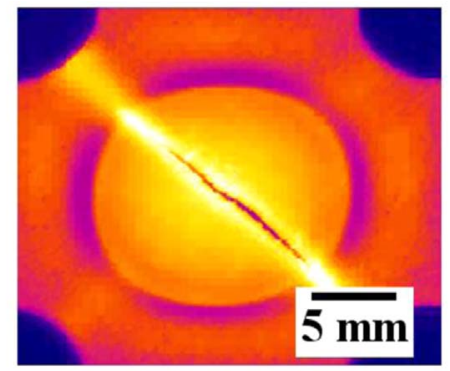

(b)

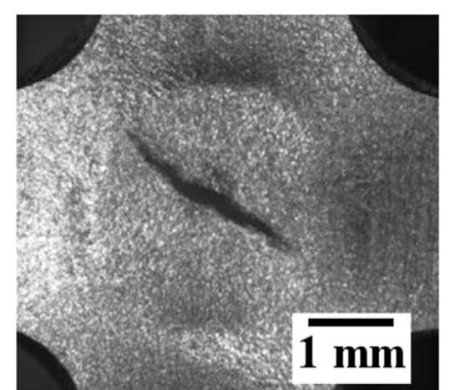

$120^{\circ} \mathrm{C}$

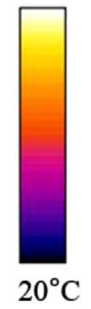

Fig. 4. a) IR image of the macroscopic cracked specimen under biaxial tensile loading, b) cracked microscopic specimen under tensile biaxial loading observed by optical microscopy. 


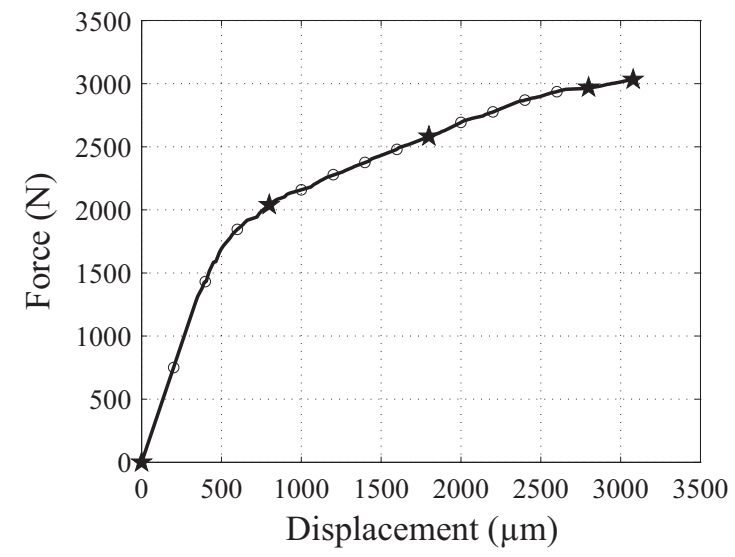

Fig. 5. Load-displacement plot recorded during the in situ biaxial tensile test operated in the SEM. Every plot point represents a loading stop off; stars indicate specific loading steps investigated in this study.

(0.32 $\mathrm{mm}$ remaining). Prior to the micromachine being set up within the SEM, a pre-test was performed in order to validate the specimen geometry.

The test was performed ex situ under an optical microscope. An equi-biaxial tensile loading was applied to the specimen until failure. This experiment was led under the same loading conditions as the in situ tests and resulted in a crack in the very center of the active part of the specimen as presented in Fig. $4 \mathrm{~b}$. The geometry was therefore validated for in situ tensile biaxial tests.

\section{Results}

\subsection{Force-displacement curve}

The resulting force-displacement curve was used to determine the different loading steps applied in the following in situ biaxial tensile loading, as shown in Fig. 5. The curve representing engineering stress as a function of strain is not presented here as the thickness reduction makes the force/section relation no more accurate. The loading performed in the SEM was therefore operated under displacement control and stopped off every $200 \mu \mathrm{m}$. Five of these strain level interruptions are investigated in this study, namely: the initial state, the fourth load (end of the elastic behavior), the ninth load (approximately at half of the strain hardening), the fourteenth load (last load before fracture) and the fifteenth load (appearance of the first crack).

At each loading stop FSD images and EBSD mappings were performed, informing on grain reorientations and misorientations, martensite formation and crack propagation.

\subsection{Microstructural evolution}

In this section, focus is made on the evolution of microstructure before failure on the first four specific loading steps. For each loading step, FSD images and data extracted by EBSD (EBSD maps and poles figures) are considered, as shown on Fig. 6. FSD images taken at different loading steps show that grain deformation induces a relief formation at the free surface. These images also show that grain with twins due to annealing are present at the initial state, but no more twin appears during loading.

Fig. 6 indicates the evolution of crystallographic texture obtained thanks to EBSD analysis for the initial state, the 4th, the 9th and the 14th loading steps. At the initial state, the specimen does not show specific texture despite the presence of coarse grains and intragranular misorientations are low. According to Fig. 6, at the end of the loading, the material shows a [101] $\mathrm{Z}$ texture with a maximum intensity factor of 4. Two main trends of grain behavior may be distinguished upon loading.

At the fourteenth load, grains show either a [101] Z orientation or important intragranular misorientations. Considering the grain numbering (Fig. 6a), grains $1-6$ present a [101] Z orientation at the final loading steps. These grains showed an initial orientation close either to the [101] or the [111] $\mathrm{Z}$ direction.

Grains 7, 8 and 9 which show a $Z$ orientation differing from [101] or [111] at the initial state do not undergo a global rotation but intragranular misorientations that strengthen with the loading. Quantitatively, the amount of grains reorienting to the [101] Z orientation reaches $60 \%$, whereas approximately $40 \%$ undergo high plastic deformation under biaxial tension.

A gradual appearance of parallel bands on the grains surface is also observed on FSD images. Upon loading, these bands get more and more numerous, thicken and appear along different directions in a same grain. They may be due either to slip systems and/or to martensite variants activation [32].

\subsection{Martensite formation}

As martensitic transformation was expected to be induced upon loading [33], EBSD data was collected at each loading step for both austenite and martensite. The two steel phases present different crystal lattices: FCC for austenite and BCC for martensite (actually, martensite presents a tetragonal lattice but the ratio between $\mathrm{c}$ and a lattice parameters is so negligible that martensite is assimilated to BCC).

Resulting phase mappings are showed on Fig. 7 represents phase distributions and grain boundaries at the initial state and at the fourteenth load. At the initial state, all grains show a uniform yellow color, meaning a fully austenitic state. Martensite formed upon loading appears in blue on the fourteenth load (cf. Fig. 7b).

At the initial state, EBSD mappings show that the specimen is fully austenitic, no evidence of martensite is found. Then, at the fourth load, the first evidence of martensite formation is detected and measured up to $0.2 \% \pm 0.05 \%$. The martensite ratio increases with the applied load: it reaches $0.4 \% \pm 0.1 \%$ at the ninth load to end at $3.8 \% \pm 0.4 \%$ at the last load before failure. In order to validate these results collected thanks to the EBSD set up, XRD phase quantification was performed on the specimen, after failure.

These measurements, carried out according to the details presented in section II, showed that the post mortem specimen contained $4 \%$ of martensite; the uncertainty on the volume fraction measurement being about $0.3 \%$. The difference of $0.2 \%$ in martensite between EBSD and XRD measures may be explained first by the different techniques used and their uncertainties, but also by the fact that EBSD results were obtained before failure and XRD measurements were made on the post mortem specimen that had undergone a slightly higher load.

\subsection{Crack propagation}

The biaxial tensile loading was applied to the specimen until the fifteenth load when the first crack appeared. An incipient crack appeared in the center of the active part and propagated along a diagonal from fillet to fillet as expected given the specimen geometry. Crack propagation occurred across the area of interest allowing the study of fracture governing mechanisms under equi-biaxial tension.

It is known that under high tensile stress, crack propagation results from two competing damage mechanisms, namely intergranular cracks (propagation along grain boundaries) and transgranular cracks (i.e. propagation through the grains) $[34,35]$. The type of crack propagation resulting from high biaxial stresses is here studied.

To begin with, the crack propagation path was identified on the FSD image obtained just after failure (cf. Fig. 8a) and drawn on the inverse pole figure map obtained by EBSD at the initial state (cf. Fig. 8b), the fourth load (cf. Fig. 8c) and the fourteenth load (cf. Fig. 8d). The crack appears to mostly propagate along grain boundaries (Fig. 8b and c), 

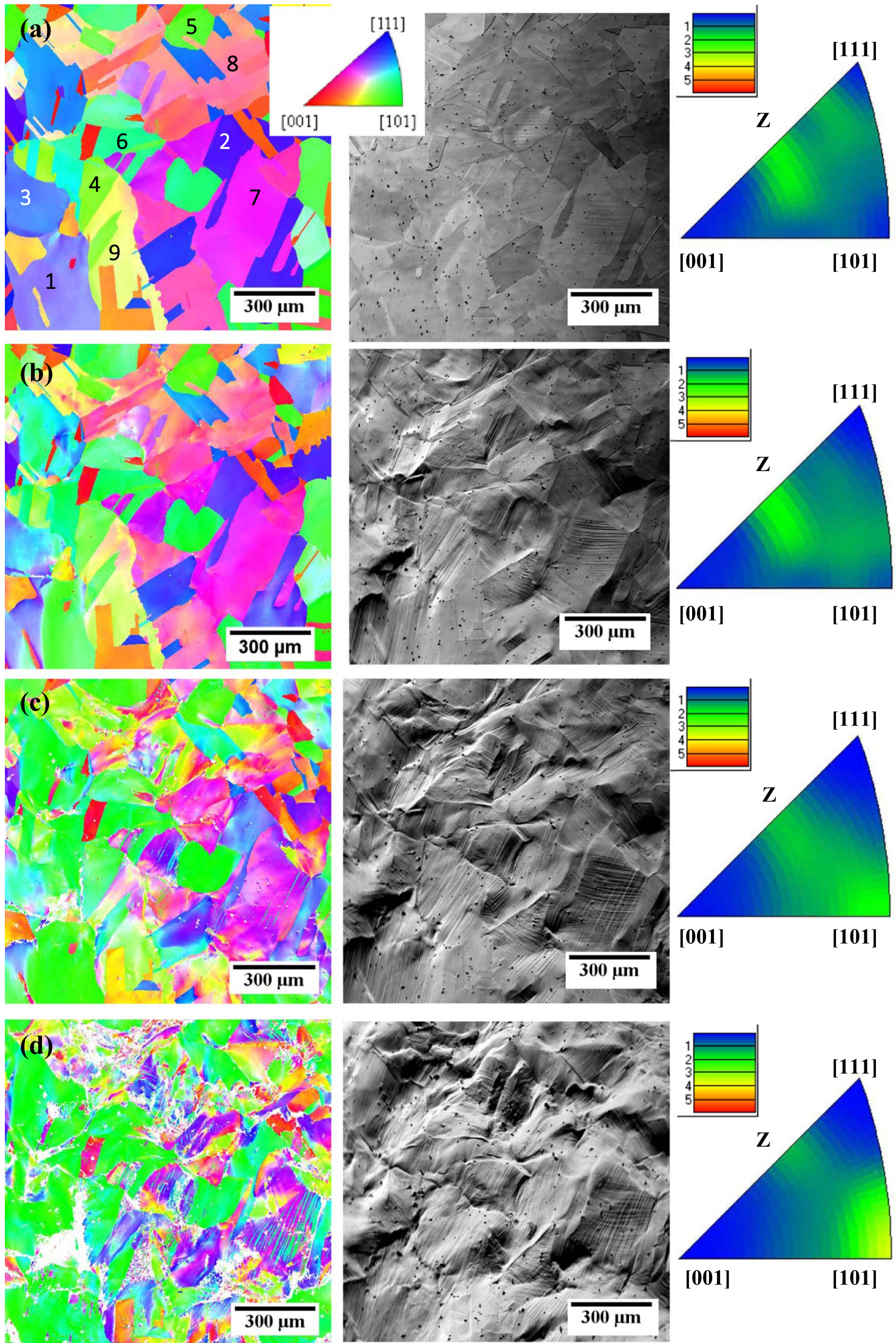

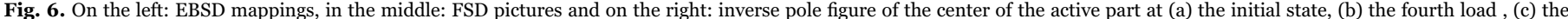
ninth load and (d) the fourteenth load. 
(a)

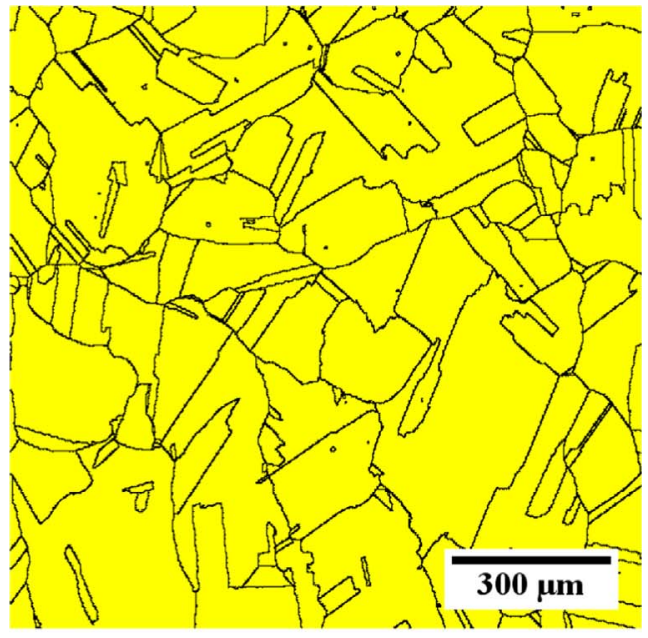

(b)

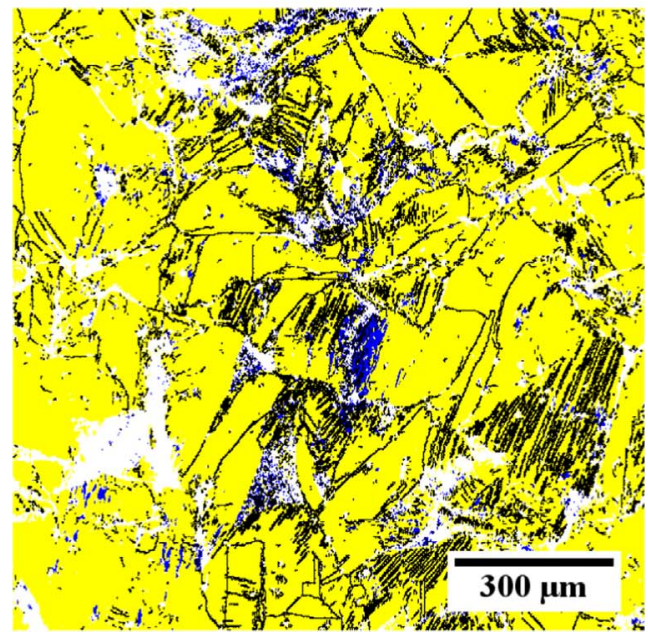

\section{Grain boundary}

\section{Austenite}

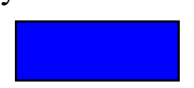

Martensite

Fig. 7. Mappings of the phase distribution obtained by EBSD (a) at the initial state and (b) at the fourteenth load, just before failure. In yellow: austenite, in blue: martensite and in black: grain boundaries.

except:

- in the upper part of the studied area where the crack propagates through high strained areas,

- in 'grain 1' (cf. Fig. 6a) encircled on Fig. 8d where the crack propagates through the grain.

\section{Discussion}

The EBSD indexation rate decreases upon loading from $100 \%$ at the first loading steps to $85 \%$ at the fourteenth load (cf. Figs. 6 and 7 by the appearance of white areas corresponding to non-indexed areas). This is due to two major effects. On the one hand, a masking effect appears with the surface relief: some parts of grains get off the surface and mask parts of other grains. This effect is magnified by the $70^{\circ}$ tilt necessary for EBSD analysis. On the other hand, EBSD indexation rate also decreases due to high strains undergone by the material and its crystal lattice. Indeed, at the end of the loading, the crystal lattice of some grains is so highly deformed that the Kikuchi bands corresponding to the diffracted signal are blurred. Then the software can no longer index the resulting patterns in these regions. However, the 15\% drop of the indexation rate is weak enough for the fourteenth load data to be handled.

\subsection{Microstructural response to tensile biaxial loading}

Results described in Sections 4.1 and 4.2 show that the biaxial tensile loading acts on microstructure at different scales. At the grain scale, loading induces grain reorientation according to the initial grain orientation. Grains with an initial orientation, close to [111] and [101] rather reorient to or close to the [101] $\mathrm{Z}$ direction, whereas grains showing other initial orientations rather display plastic deformation. At the intragranular level, EBSD analysis shows that non-reoriented grains develop large deformations noticeable thanks to high intragranular misorientations.

Evidence of martensite formation upon loading has been made by both EBSD and post mortem XRD. According to results shown in Sections 4.2 and 4.3, it seems clear that martensite is localized in highly deformed areas. So either martensite formation leads to important lattice deformations in its neighborhood, or high intragranular misorientations induce the formation of martensite. No evidence of martensite formation is found in grains reorienting to a [101] $\mathrm{Z}$ orientation.

Some slip bands are present at the initial state due to mechanical polishing. Other slip bands appear during loading whether in reorienting and in grains presenting high misorientations. Some grains such as grain 7 even show cross slip due to the activation of two different slip systems, maybe due to the initial orientation and the influence of the surrounding grains.

Thus the material accommodates tensile biaxial loading by both intergranular and intragranular mechanisms: grain rotations and misorientations coupled to plasticity and martensitic transformation.

It has been shown previously that initial grain orientation has a great influence on its behavior upon biaxial tensile loading. The same statement was observed under uniaxial tension by Chakrabarty et al. [36] and modeled by Raabe et al. [37]. Both authors observed a strong influence of the initial crystallography on misorientations development.

Another noteworthy result here is that by performing a uniaxial tensile loading path, the grain reorientation would have been expected in the [100] $\mathrm{Z}$ orientation. Under the biaxial tensile loading path here presented, the grain reorientation happens rather toward the [101] Z orientation showing that a change in the loading path induces a change in the microstructure evolution trend.

The instability of austenite in fully austenitic AISI 304 stainless steels makes it possible to form strain-induced martensite. This unstable austenite is sensitive to many factors such as temperature, loading path and stress triaxiality whereas grain size was shown not to affect the amount of deformation-induced martensite [38]. RodríguezMartínez et al. [39] uniaxially loaded a material showing the same chemical composition and finer grains than the one used in this study. In the case of this particular loading, the fine-grain 304 stainless steel produced a volume fraction of martensite of approximately $70 \%$ in the necking area. In the present study the maximum volume fraction of martensite formed under biaxial tension reaches $4 \%$ and has been measured by XRD on the crack boundary. It appears therefore that loading path has a great influence on martensitic transformation ratio. Thus it seems that biaxial tension is less favorable to martensitic transformation than uniaxial tension. However one has to be aware that comparing these two loading paths at equal deformation is not so simple due to the thickness reduction of the biaxial specimen.

\subsection{Crack propagation upon biaxial tensile loading}

As expected for the ductile fracture of stainless steel at room temperature, plastic deformation occurred by transgranular slip during loading until it culminated in the formation and propagation of a crack along strain localization regions. A transgranular crack propagation mode is then expected due to the ductile fracture. However, according 
(a)

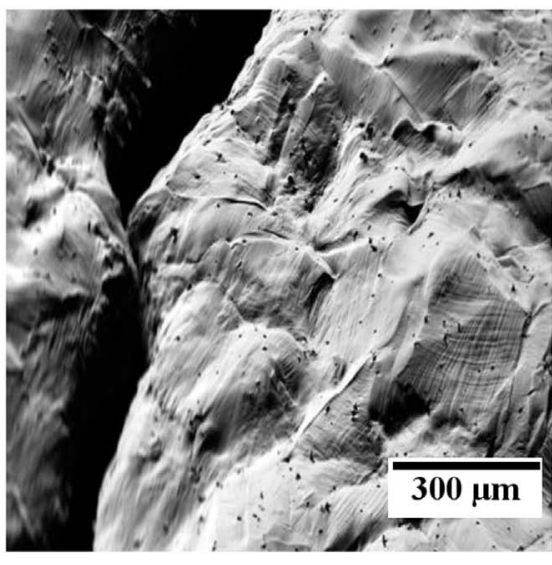

(c)

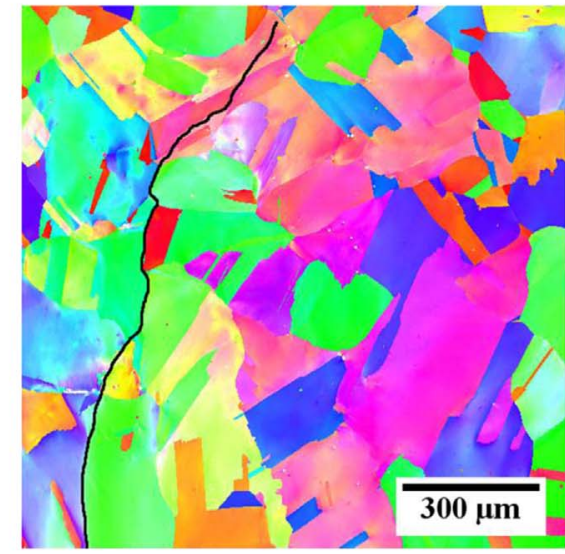

(b)

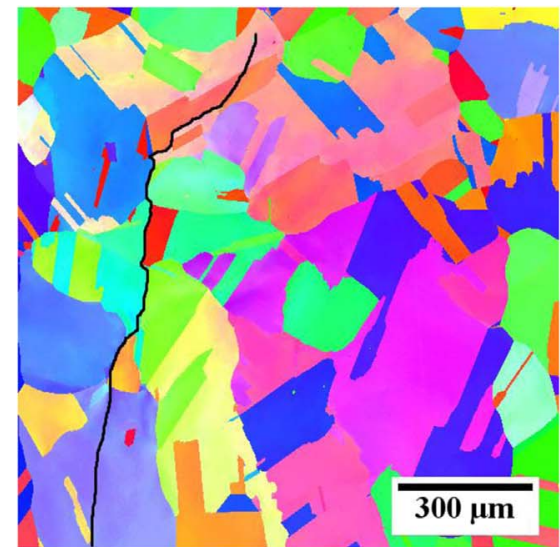

(d)

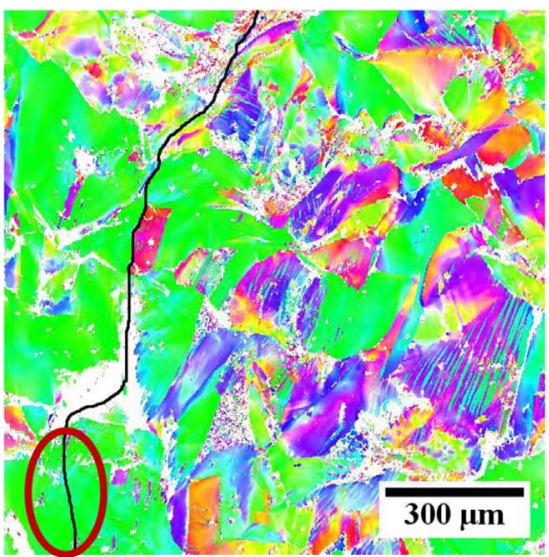

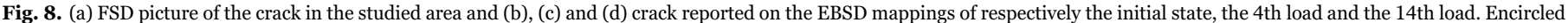
in red on the 14th load: intragranular crack propagation in grain ' 1 '.

to Fig. $8 \mathrm{~b}$ and c, the crack appears to mostly propagate along grain boundaries. This unexpected crack propagation mode may occur under ductile fracture of a heat treated material. In the present study, the annealing operated to increase the grain size may have caused segregation of certain impurities to the grain boundary [35], thereby embrittling the material at the grain boundary level.

It has been shown that transgranular cracks initiate near grain boundaries, when intergranular propagation becomes barely possible due to the local geometrical arrangement [40]. Concerning the crack propagation in high strained areas, the notions of grain and grain boundary no longer make sense at the very last loading steps (cf. Fig. 8d). Thus the reporting of crack propagation on the first EBSD mappings in the upper area undergoing very high strains and intragranular misorientations does not mean that the crack propagated through the grains, but through a deeply deformed lattice. This shows that the energy needed to propagate the crack through these highly strained areas is lower than along embrittled grain boundaries.

Focus is now made on the evolution of 'grain 1' orientation upon loading. At the initial state, except two localized twins, this grain shows

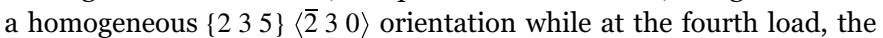
initial grain splits into two sub-grains showing respectively $\left\{\begin{array}{lll}2 & 1 & 3\end{array}\right\}\langle\overline{8} 131\rangle$ and $\left\{\begin{array}{llll}2 & 0 & 3\end{array}\right\}\langle\overline{3} 62\rangle$ grain orientation. Finally, the grain orientation returns to homogeneity at the fourteenth load with the

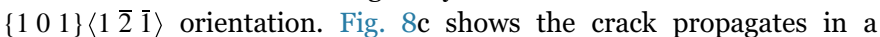
transgranular mode along the boundary between the two sub-grains of 'grain 1' appearing at the fourth load. Thus even if 'grain 1' appears to be completely homogeneous on the EBSD maps just before failure (cf. Fig. 6d), the crack propagates through some intragranular discontinuity undetected by the EBSD framework.

\section{Conclusion}

In this work the microstructural evolution of coarse grain AISI 304 stainless steel sheets subjected to biaxial tension has been experimentally studied. Conclusions of this study can be summed up as follows:

- A specimen geometry allowing for biaxial stress state and crack initiation in the center of the active part was designed at the macroscopic scale. Once the geometry was validated on a test bench, it was adapted to the microscopic scale in order to fit the micromachine for in situ biaxial tensile testing.

- At the grain level, it was shown that initial grain orientation has a strong influence on grain behavior upon loading. Depending on their initial orientation, some grains underwent high plastic deformation whereas other grains gradually rotated to a [101] Z orientation. Quantitatively, 60\% of grains rotated to the [101] Z orientation, whereas $40 \%$ of the grains deformed plastically.

- Coupled EBSD and XRD measurements of the austenite volume fraction showed that large deformations were accommodated by both phase transformation and plasticity. About $4 \%$ of martensite was formed in the active part under biaxial tension.

- Crack propagation was shown to mostly occur at grain boundaries in an intergranular cracking mode. Except for high strained areas where notions of "grain" and "grain boundary" are difficult to apply.

This research did not receive any specific grant from funding agencies in the public, commercial or not-for-profit sectors.

\section{References}

[1] J.J. Roa, J.M. Wheeler, T. Trifonov, G. Fargas, A. Mateo, J. Michler, E. JiménezPiqué, Deformation of polycrystalline TRIP stainless steel micropillars, Mater. Sci. 
Eng. A 647 (2015) 51-57.

[2] Z. Ma, H. Zhao, X. Hu, H. Cheng, S. Lu, L. Zhang, Influences of tensile pre-strain and bending pre-deflection on bending and tensile behaviors of an extruded AZ31B magnesium alloy, Mater. Des. 64 (2014) 566-572.

[3] R. Muñoz-Moreno, E.M. Ruiz-Navas, C.J. Boehlert, J. Lorca, J.M. Torralba, M.T. Pérez-Prado, Analysis of crystallographic slip and grain boundary sliding in a Ti-45Al-2Nb-2Mn (at\%)-0.8vol\% $\mathrm{TiB}_{2}$ alloy by high temperature in mechanical testing, Mater. Sci. Eng. A 606 (2014) 276-289.

[4] E.Y. Guo, M.-Y. Wang, T. Jing, N. Chawla, Temperature-dependent mechanical properties of an austenitic-ferritic stainless steel studied by in situ loading in a scanning electron microscope (SEM), Mater. Sci. Eng. A 580 (2013) 159-168.

[5] A. Vaz-Romero, J.A. Rodríguez-Martínez, A. Arias, The deterministic nature of the fracture location in the dynamic tensile testing of steel sheets, Int. J. Impact Eng. 86 (2015) 318-335.

[6] A.S. Taylor, P.D. Hodgson, Dynamic behavior of 304 stainless steel during high Z deformation, Mater. Sci. Eng. A 528 (2011) 3310-3320.

[7] A. Reichardt, M. Ionescu, J. Davis, L. Edwards, R.P. Harrison, P. Hosemann, D. Bhattacharyaa, In situ micro tensile testing $\mathrm{He} 2+$ ion irradiated and implanted single crystal nickel film, Acta Mater. 100 (2015) 147-154.

[8] Y. Dong, B.H. Sencer, F.A. Garner, E.A. Marquis, Microchemical and microstructural evolution of AISI 304 stainless steel irradiated in EBR-II at PWR-relevant dpa rates, J. Nucl. Mater. 467 (2015) 692-702.

[9] H. Borkar, S. Seifeddine, A.E.W. Jarfors, In-situ EBSD study of deformation behavior of Al-Si-Cu alloys during tensile testing, Mater. Des. 84 (2015) 36-47.

[10] S. Wang, Y. Zhang, C. Schuman, J.-S. Lecomte, X. Zhao, L. Zuo, M.-J. Philippe, C. Essling, Study of twinning/detwinning behaviors of Ti by interrupted in situ tensile tests, Acta Mater. 82 (2015) 424-436.

[11] C.J. Boehlert, Z Chen, I. Gutiérrez-Urrutia, J. Llorca, M.T. Pérez-Prado, In situ analysis of the tensile and tensile-creep deformation mechanism in rolled AZ31, Acta Mater. 60 (2012) 1889-1904.

[12] V. Livescu, J.-F. Bingert, C. Liu, M.L. Lovato, B.M. Patterson, Biaxial deformation in high purity aluminum, Mater. Sci. Eng. A 648 (2015) 330-339.

[13] L. Mattei, D. Daniel, G. Guiglionda, H. Klöcker, J. Driver, Strain localization and damage mechanisms during bending of AA6016 sheet, Mater. Sci. Eng. A 559 (2013) 812-821.

[14] D.M. Collins, M. Mostafavi, R.I. Todd, T. Connolley, A.J. Wilkinson, A synchrotron X-ray diffraction of in situ biaxial deformation, Acta Mater. 90 (2015) 46-58.

[15] T.O. Erinosho, D.M. Collins, R.I. Todd, F.P.E. Dunne, Assessment of X-Ray diffraction and crystal plasticity lattice strain evolution under biaxial loading, Int. J. Plast. 83 (2016) 1-18.

[16] T. Marin, P.R. Dawson, M.A. Gharghouri, R.B. Rogge, Diffraction measurements of elastic strains in stainless steel subjected to in situ biaxial loading, Acta Mater. 56 (2008) 4183-4199.

[17] S. Van Petegem, J. Wagner, T. Panzner, M.V. Upadhyay, T.T.T. Trang, H. Van Swygenhoven, In-situ neutron diffraction during biaxial deformation, Acta Mater. 105 (2016) 404-416.

[18] Metallic Materials - Tensile Testing - Part1: Method of Test at Room Temperature, ISO 6892-1, 2009.

[19] Standard Test Method for Flexural Strength of Advanced Ceramics at Ambient Temperature, ASTM C1161-02Ce1, ASTM International 2002.

[20] Metallic Materials - Sheet and Strips - Biaxial Tensile Testing Method using a Cruciform Test Piece, ISO 16842, 2014

[21] R. Xiao, X.-X. Li, L.-H. Lang, Y.-K. Chen, Y.-F. Yang, Biaxial tensile testing of cruciform slim superalloy at elevated temperatures, Mater. Des. 94 (2016) $286-294$.

[22] M. Kubo, H. Yoshida, A. Uenishi, S. Suzuki, Y. Nakasawa, T. Hama, H. Takuda,
Development of biaxial tensile test system for in-situ scanning electron microscope and electron backscatter diffraction analysis, ISIJ Int. 56 (2016) 669-677.

[23] J.A. Rodríguez-Martínez, A. Rusinek, R. Pesci, Experimental survey on the behavior of AISI 304 steel sheets subjected to perforation, Thin Wall Struct. 48 (2010) 966-978.

[24] Standard Practice for X-Ray Determination of Retained Austenite in Steel with Near Random Crystallographic Orientation, ASTM E975 - 13, ASTM International 2013.

[25] K. Prasad, P.S. Karamched, A. Bhattacharjee, V. Kumar, K.B.S. Rao, M. Sundararaman, Electron back scattered diffraction characterization of thermomechanical fatigue crack propagation of a near a titanium alloy Timetal 834, Mater. Des. 65 (2015) 297-311.

[26] Z. Ktari, Z. Tourki, H. Sidhom, M.A. Gahbiche, On the interaction between transformation induced plasticity and the austenitic stainless steel anisotropy (AISI 304) under shear loading path, Mater. Des. 32 (2011) 3765-3771.

[27] A. Makris, T. Vandenbergh, C. Ramault, D. Van Hemelrijck, E. Lamkanfi, W. Van Paepegem, Shape optimization of a biaxially loaded cruciform specimen, Polym. Test 29 (2009) 216-223.

[28] Y. Yu, M. Wan, X.-D. Wu, X.-B. Zhou, Design of a cruciform biaxial tensile specimen for limit strain analysis by FEM, J. Mater. Process. Technol. 123 (2002) 67-70.

[29] T. Kuwabara, S. Ikeda, K. Kuroda, Measurement and analysis of differential work hardening in cold-rolled steel sheet under biaxial tension, J. Mater. Process. Technol. 80-81 (1998) 517-523.

[30] Y. Hanabusa, H. Takisawa, T. Kuwabara, Numerical verification of a biaxial tensile tests method using a cruciform specimen, J. Mater. Process. Technol. 213 (2013) 961-970.

[31] R. Baptista, R.A. Claudio, L. Reis, J.F.A. Madeira, I. Guelho, M. Freitas, Optimization of cruciform specimens for biaxial fatigue loading with direct multi search, Theor. Appl. Fract. Mech. 80 (2015) 65-72.

[32] A. Kermanpur, P. Behjati, J. Han, A. Najafizadeh, Y.-K. Lee, A microstructural investigation on deformation mechanisms of Fe-18Cr-12Mn-0,05C metastable austenitic steels containing different amounts of nitrogen, Mater. Des. 82 (2015) $273-280$.

[33] P. Haušild, V. Davydov, J. Drahokoupil, M. Landa, P. Pilvin, Characterization of strain-induced martensitic transformation in a metastable austenitic stainless steel, Mater. Des. 31 (2010) 1821-1827.

[34] S.M. Taheri Mousavi, N. Richart, C. Wolff, J.F. Molinari, Dynamic crack propagation in a heterogeneous ceramic microstructure, insights from a cohesive model, Acta Mater. 88 (2015) 136-143.

[35] A.F. Liu, Mechanics and Mechanisms of Fracture: An Introduction, ASM International, 2005.

[36] S. Chakrabarty, S.K. Mishra, P. Pant, Crystallographic orientation and boundary effects on misorientations development in austenitic stainless steel, Mater. Sci. Eng. A 617 (2014) 228-234.

[37] D. Raabe, Z. Zhao, S.-J. Park, F. Roters, Theory of orientation gradients in plastically strained crystals, Acta Mater. 50 (2002) 421-440.

[38] Y. Mastuoka, T. Iwasaki, N. Nakada, T. Tsuchiyama, S. Takaki, Effect of grain size on thermal and mechanical stability of austenite in metastable austenitic stainless steel, ISIJ Int. 53 (2013) 1224-1230.

[39] A. Kisko, R.D.K. Misra, J. Talonen, L.P. Karjalainen, The influence of grain size on the strain-induced martensite formation in tensile straining of an austenitic $15 \mathrm{Cr}$ 9Mn-Ni-Cu stainless steel, Mater. Sci. Eng. A 578 (2013) 408-416.

[40] A. Musienko, G. Cailletaud, Simulation of inter- and transgranular crack propagation in polycrystalline aggregates due to stress corrosion cracking, Acta Mater. 57 (2009) 3840-3855. 